WOLFGANG BRÜCKLE

\title{
Was nicht im Baedeker steht \\ Fotografie und Großstadtphysiognomik in der Zwischenkriegszeit
}

Im hermeneutischen Diskurs der Weimarer Republik hatte Alles und Jedes Ausdruck und Physiognomie. Natürlich sind Verfahren und Metapher physiognomischer Betrachtungsweise althergebracht. Schon lange hatte man physiognomischen Ausdruck für die Erhellung von Charakter, Geisteszustand, Rasse und Verbrechen in meist pseudowissenschaftlichen Debatten zu nutzen versucht. Aber in der Zwischenkriegszeit gab es nach Überzeugung tonangebender deutschsprachiger Kulturkritiker und in Erweiterung jenes Ansatzes wohl keine Erscheinung der Welt, die nicht einer Oberflächenlektüre unterzogen werden konnte und die nicht in ihrem Zuge Aufschluss über verborgene Lebenszusammenhänge geben konnte. Die Krise der Nachkriegszeit erzeugte den Wunsch nach einer Verortung der gegenwärtigen Kultur und entzog deren Exegeten zugleich die hergebrachten Kriterien zur Unterscheidung zwischen lesenswertem Stoff und Nebensächlichkeiten. Auf dieser Grundlage drängte sich wohl die Wahrnehmung aller Alltagsphänomene als gleichermaßen ausdrucksvolle Erscheinungen auf. Die Fotografie war in der hergebrachten Physiognomik oft als Hilfsmittel verwendet worden. Sie trug auch viel zur physiognomischen Lektüre des zeitgenössischen Lebensumfelds bei. Ihre angebliche Wiedergabetreue und ihre Beschränkung auf die Erscheinungen der Außenwelt machte sie zu einem willkommenen Werkzeug in den Händen von Kulturkritikern, die nach dem Charakteristischen suchten und sich doch nicht nachsagen lassen wollten, sie verzerrten die Welt durch die Auswahl von deren Einzelzügen. Es kommt deshalb nicht überraschend, dass viele zeitgenössische Veröffentlichungen, die sich eines erweiterten Begriffs von 'Gesichtserfassung bedienen, die vermeintliche Beweisfähigkeit der Fotografie zu nutzen suchen. Landschaften, Krieg, das demokratische Gemeinwesen und die damalige Gegenwart überhaupt hatten sich angeblich, wie Siegfried Kracauer von ihnen sagte, ein "Photographiergesicht" zugelegt. ${ }^{1}$ Das galt auch für komplexe Gebilde wie die Stadt.

1 Siegfried Kracauer: Die Fotografie [1927], in: ders.: Essays. Feuilletons. Rezensionen (Werke 5), hg. von Inka Mülder-Bach, 4 Bde., Frankfurt a.M. 2011, Bd. 2, S. 682-698, hier S. 693. 
Eine schwer zu überschauende Menge Bilderbücher über diesen Gegenstand kam damals auf den Markt, und eine der Buchreihen, die großen Zuspruch fanden, hieß bezeichnend genug »Das Gesicht der Städte«. Sie und ähnliche Verlagsangebote zeugen von der Vorstellung, dass urbane Räume einen je eigenen Charakter haben, sei er auch in fortwährender Wandlung begriffen, und dass sie imstande sind, ihn der fotografischen Linse mitzuteilen. Im Folgenden wird beschrieben, wie sich im deutschen physiognomischen Denken der Zwischenkriegszeit die Belehnung städtischer Erfahrung mit Bedeutung und die Theoretisierung des Mediums Fotografie kreuzten. Die Flanerie des modernen Stadtbewohners war nicht weniger eine Funktion der Betrachtung von Fotografien als ein Anlass für deren Anfertigung, und es steht zu vermuten, dass die Medieneigenschaften der Fotografie die physiognomische Untersuchung von städtischen Umgebungen besonders befördert hat.

Fotografen konnten die Stadt metaphorisieren wie etwa Aenne Biermann auf einem Bildnis, das um 1931 die Gesichtszüge einer Frau so mit einem Straßenzug verbindet, dass nicht mehr zwischen der Übertragung von Eigenschaften des Individuums auf die Stadt und umgekehrt der Stadt auf das Individuum zu unterscheiden ist, oder wie wir es in einem Beitrag für Scherl's Magazin von 1928, dessen Verfasser auf die Vorzüge technologisch fortschrittlicher Filmkameras verweist, erkennen können (Abb. 1). ${ }^{2}$ Deren prismatische Bilder lassen, so sagt er, die symbolischen Aspekte des Lebens in der Metropole mit ihrem visuellen Chaos und ihrer Geschwindigkeit in den Vordergrund treten. Der Aufsatz ist offensichtlich von Walter Ruttmanns Berlin. Symphomie der Gro/sstadt angeregt. Unter den beigegebenen Abbildungen finden sich auch Fotografien von nächtlichen Straßen, geliefert von Otto Umbehr und Albert Vennemann. Sie sind konventioneller gehalten als die UFA-Einzelkader, neben denen sie im besagten Aufsatz stehen; das gilt insbesondere für Vennemanns Beitrag. Dem Verfasser zufolge tragen auch sie zu den phantastischen Eindrücken der modernen Stadt bei. Zu dieser Bemerkung mag die Betonung künstlicher Beleuchtung auf den Bildern Anlass gegeben haben, aber als symbolisch bedeutsamer Beitrag zur rgestaltenden Sicht auf die Stadt erscheinen sie doch hauptsächlich wegen ihrer Verbindung mit den Filmexperimenten und dem Begleittext. Tatsächlich lässt sich zeigen, dass Vennemanns Bilder im Zusammenhang mit Kracauers

2 Vgl. Hermann Treuner: Vision der Großstadt, in: Scherl's Magazin 4 (1928), S. 922-926, hier S. 924, und Herbert Molderings: Umbo. Otto Umbehr, 1902-1980, Düsseldorf 1995, S. 97f. Für Biermanns Doppelbelichtung vgl. Aenne Biermann: Fotografien 1925-33, hg. von Ute Eskildsen, Berlin 1987, S. 66. 


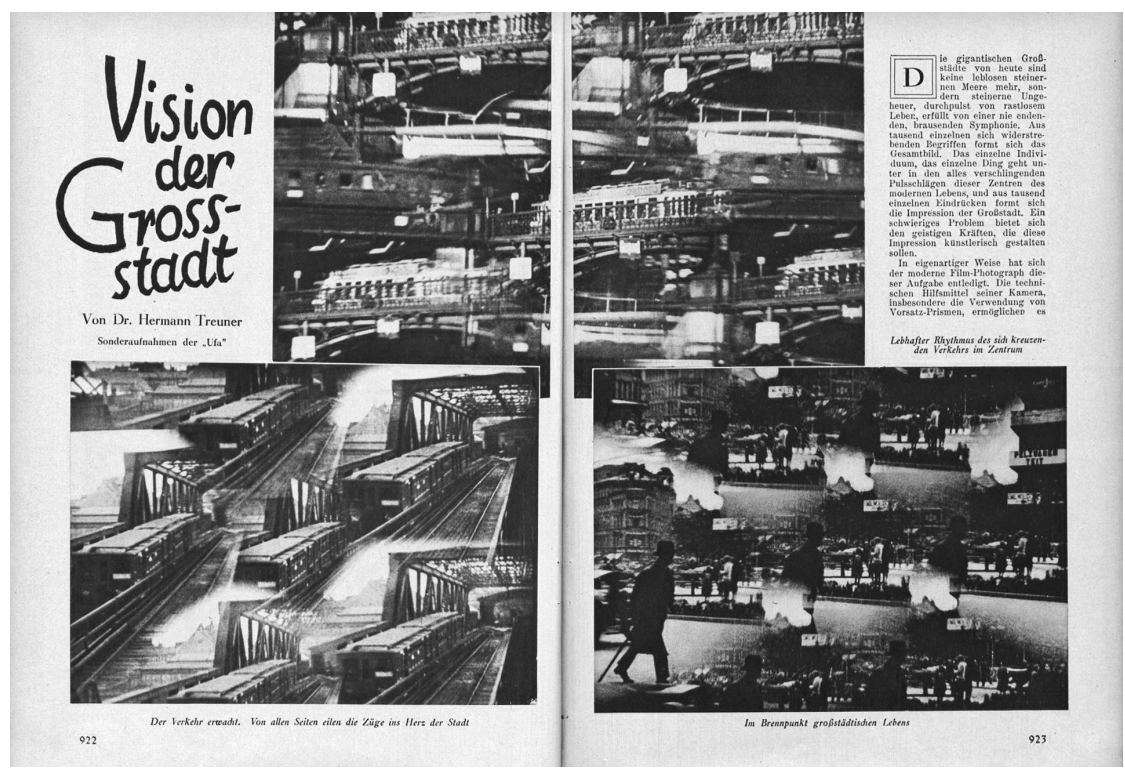

Abb. 1: Hermann Treuner: Vision der Gro/sstadt, in: Scherl's Magazin 4 (1928), S. $922 f$.

Erschließung der Großstadt eine ganz andere Rolle spielen. Wir kommen deshalb am Ende wieder auf sie zurück. Festzuhalten ist an dieser Stelle, dass sich das metaphorische Gesicht der Stadt auch in vernachlässigten Erscheinungen des Alltags entdecken und unter Vernachlässigung modernistischer Gestaltungsmittel darstellen ließ. Eine damals beliebte Reiseführer-Reihe trug den Titel Was nicht im Baedeker steht, woraus man leicht ein wachsendes Interesse an einer neuen Bestimmung der identitätsbildenden Merkmale von Städten entnehmen kann. Einige Fotografen gaben in diesem Sinn Beispiele für die Erforschung des Flüchtigen, Übersehenen, vermeintlich Bedeutungslosen. Die Lesbarkeit ihrer Bilderzählungen ergab sich ebenfalls aus einem auf charakteristische Züge abhebenden, meist mehr oder weniger deutlich metaphorisierenden Begleittext. Sie beruhte im Übrigen aber weniger auf der kunstbeflissenen Verdichtung als auf einer fortwährenden Ergänzung des Rahmenthemas 'Stadt um immer neue Gegenstände, sei es innerhalb der Einzelveröffentlichungen oder in dem Zusammenhang, der sich für die Leserschaft der Illustrierten aus dem übergreifenden visuellen Diskurs der Stadt ergab. Dafür wurde oft die Haltung eines Flaneurs eingenommen und auf die Begegnung mit dem Zufall vertraut (Abb. 2). Es ist gut bekannt, dass dieses Verfahren der Großstadterkundung in Berlin von Schriftstellern wie 


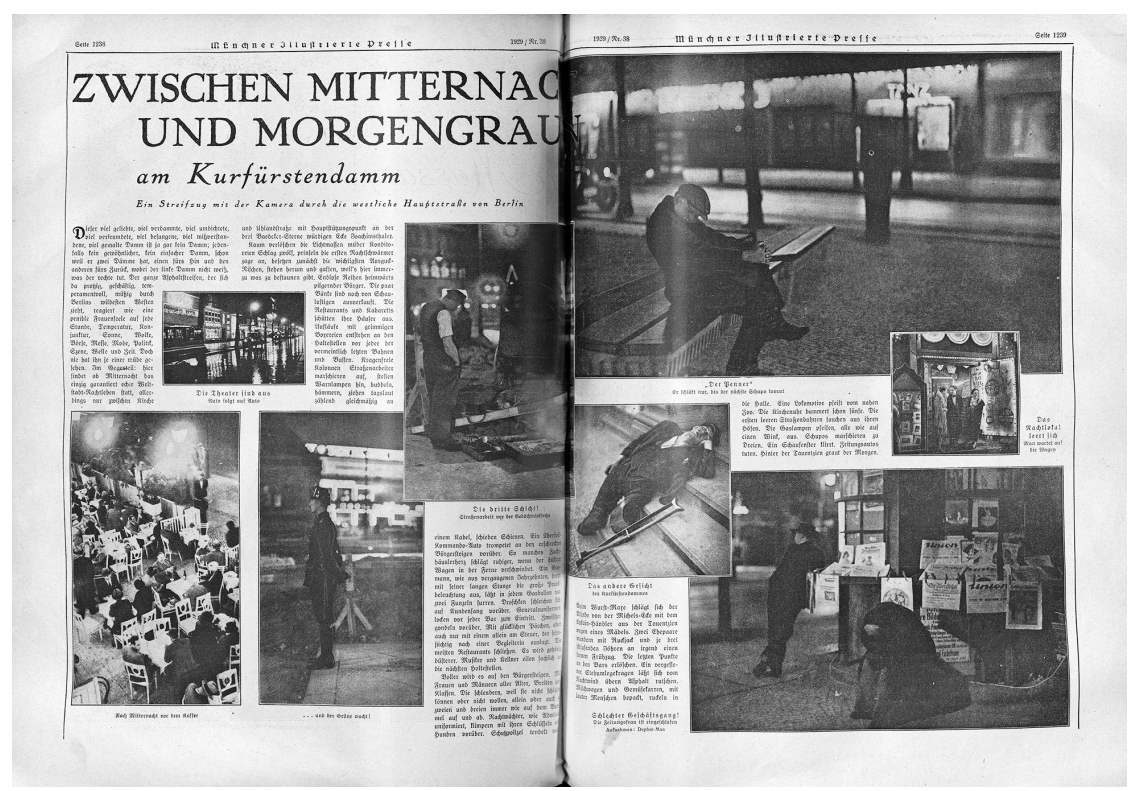

Abb. 2: Felix H. Man: Zwischen Mitternacht und Morgenrauen, in:

Münchner Illustrierte Presse 6 (1929), Nr. 38, S. $1238 f$.

Walter Benjamin und Franz Hessel wiederbelebt wurde, mehr theoretisch in Benjamins Schriften und mehr performativ bei Hessel, der die Erfassung von Erscheinungen, »die kein Reisebuch verzeichnet«, zur Grundlage seiner Arbeit machte. Kracauer beanspruchte für sich ganz ähnlich eine zufallsgeleitete Betrachtungsweise, die sich den im Baedeker hervorgehobenen Blickachsen und Sehenswürdigkeiten entzieht. ${ }^{3}$ Dieselbe Zielsetzung wurde, wie wir an Titel- und Motivwahl vieler sogenannter Bildessays in den Zeitschriften der Zeit erkennen können, auch von Fotografen übernommen. Die Rede von "Streifzug « und »Fotobummel« diente in solchen Fällen als begrifflicher Fingerzeig auf eine Haltung, in der die Urheber der Bilder unverhoffte Funde zu machen hofften und, wie man mit Rücksicht auf das Paradigma der physiognomischen Lektüre hinzufügen kann, die Stadt als ausdrucksbefähigtes Gegenüber, dessen Züge jedoch erst gedeutet werden müssen, wahrnehmen

3 Franz Hessel: Spazieren in Berlin, Berlin 1929, S. 92, und Siegfried Kracauer: Berliner Landschaft [1931], in: ders.: Essays, Feuilletons, Rezensionen, Bd. 3, S. 700-702, hier S. 700. Siehe auch Susanne Müller: Die Welt des Baedeker. Eine Medienkulturgeschichte des Reiseführers 1830-1945, Frankfurt a.M./New York 2012, bes. S. $221 f$. 
wollten. ${ }^{4}$ Aus Sicht des Fotografen waren in diesem Zusammenhang Lektüre und Repräsentation des Gesichts der Stadt kaum noch unterscheidbar. Es gibt wohl keinen besseren Beleg dafür als Vennemanns Behauptung, dass eine einfache Fotografie einer dörflich wirkenden Ecke im alten Stadtkern und seine offensichtlich gestaltete Montage von einigen Berliner Sehenswürdigkeiten beide das »Antlitz Berlins" vergegenwärtigen (Abb. 3). Wir werden aber sehen, dass dieselbe Überlagerung von Erfahrung und Gestaltung auch innerhalb verfremdungsfreier Fotografien auftrat.

\section{DIE PHYSIOG\OMIE ZWEIER STÄDTE?}
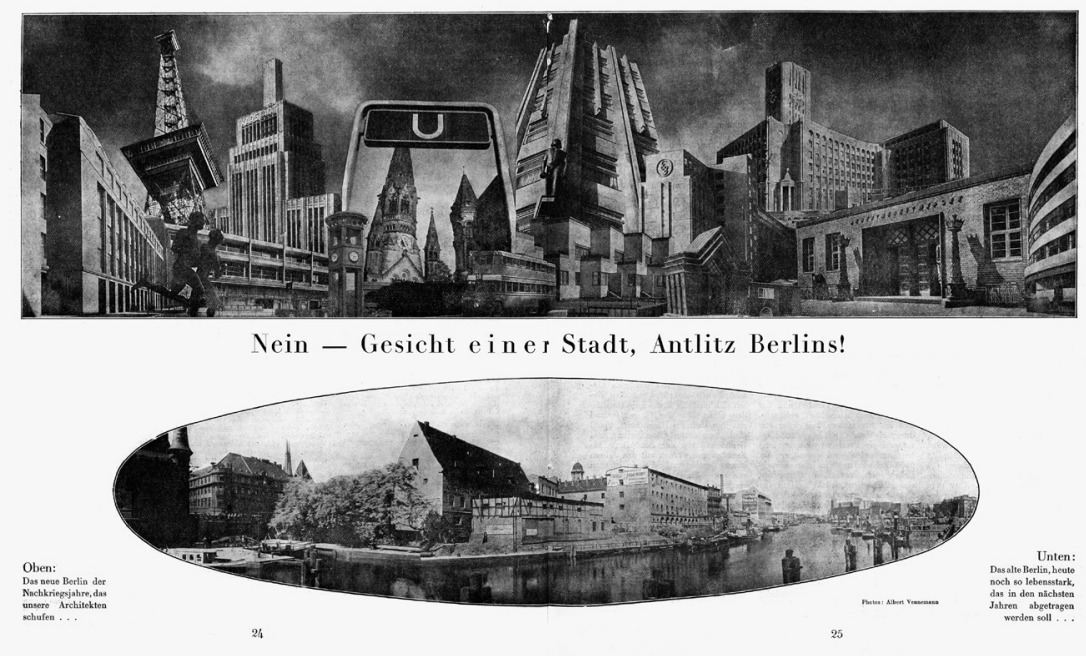

Abb. 3: Albert Vennemann: Die Physiognomie zweier Städte?, in:

Der Berliner 1 (1929), Nr. 2, S. 24 f.

4 Vgl. Felix H. Man: Zwischen Mitternacht und Morgengrauen, in: Münchner Illustrierte Presse 6 (1929), Nr. 38, S. 1238-1240, und Friedrich Seidenstücker: Photobummel rund um Kopenhagen, in: Berliner Illustrirte Zeitung 43 (1934), Nr. 31, S. 1122-1123. Letztere Veröffentlichung behandelt Wolfgang Brückle: Bummeln mit der Kamera. Seidenstückers Berliner Straßenleben, in: Von Nilpferden und anderen Menschen. Berlin in Fotografien von Friedrich Seidenstücker (1928-1961), hg. von Ulrich Domröse, Berlin 2011, S. $160-171$, S. $166 f$. 
Wohlgemerkt lässt sich weder die künstlerische Verdichtung noch die Inszenierung des Blicks eines Flaneurs leicht auf eine jeweils bestimmte Bildauffassung eingrenzen. Ganz unterschiedliche Stile bestehen im selben Interesse am Physiognomischen nebeneinander her. Überhaupt ist es nicht leicht, die fotografischen Entscheidungen widerspruchsfrei zu kategorisieren. Im Jahr 1928 veröffentlichte Albert Renger-Patzsch im Auftrag der örtlichen Tourismusbehörde ein Buch über Lübeck. Seine Bilder sind sämtlich neusachlich gehalten. Aber im Buch übernehmen sie eine mehrdeutige Rolle. Das Werk bietet eine Chronologie und ein Inventar; es bildet einen Essay und ein Archiv. Es stellt sowohl ein Ergebnis persönlichen Erlebens wie von verallgemeinernden Erwägungen dar, jedenfalls wenn wir uns dem Kunsthistoriker Carl Georg Heise, der die Einleitung schrieb, anschließen wollen. Er versucht, das Wesen von Renger-Patzschs Bilderreihe zu fassen, indem er sie auf das, was er das "Gesicht « der Stadt nennt, bezieht. ${ }^{5}$ Dieses Gesicht ist deutlich, sagt er, hat aber wandelbare Züge. So weit kommen wir noch mit einer Vorstellung von Fotografie als neutral gehaltenem Tatsachenspeicher aus. Aber dann spricht Heise von der persönlichen Erfahrung. Es sei das Antlitz, also die Oberfläche der Stadt, die der zeitgenössische Reisende sehen will. Ob als Fußgänger oder als Autofahrer, er wolle immer nur sehen. In Heises Augen ist Renger-Patzsch imstande, für diese Welterfassungstätigkeit eine Anleitung zu liefern, indem er die Stadt ganz neu entdeckt und dabei Raum für des Betrachters eigene Entdeckungen schafft. Die altbekannten Anziehungspunkte der Stadt stehen nicht mehr als solche im Mittelpunkt. Scheinbar unwichtige Dinge erhalten Bedeutung auf einer Fotografie, die das angeblich Typische in ihnen hervorkehrt. Pflasterung, Türklopfer, Regenrinne haben die Macht, das große Ganze erlebbar zu machen (Abb. 4). Der Fotograf ist so verfahren, sagt Heise, weil auch der heutige Reisende von einer Erforschung der Einzelheiten "blitzartig « zu Einsichten in die Bedeutung der großen Zusammenhänge komme. Diese Behauptung muss jedem, der mit Benjamins Konzept der Flanerie und der an sie gebundenen Erkenntnisform vertraut ist, bekannt erscheinen: Da ist die Erleuchtungsmetapher, da ist das nur vom geübten Auge erkennbare Detail, da ist die in der Fülle der Erscheinungen verborgene Bedeutung. Die Ähnlichkeiten, die Heise zwischen den einzelnen Fotografien in Renger-Patzschs Bildstrecke ausmacht, sind zwar nicht dieselben, nach denen Benjamin Ausschau zu halten pflegte. Heise betont das friedliche Beieinander von Altem und

5 Carl Georg Heise: [Einleitung], in: Lübeck. Achtzig photographische Aufnahmen von Albert Renger-Patzsch, hg. von Ernst Timm, Berlin 1928, S. 7-15, hier S. 7 und 14. 


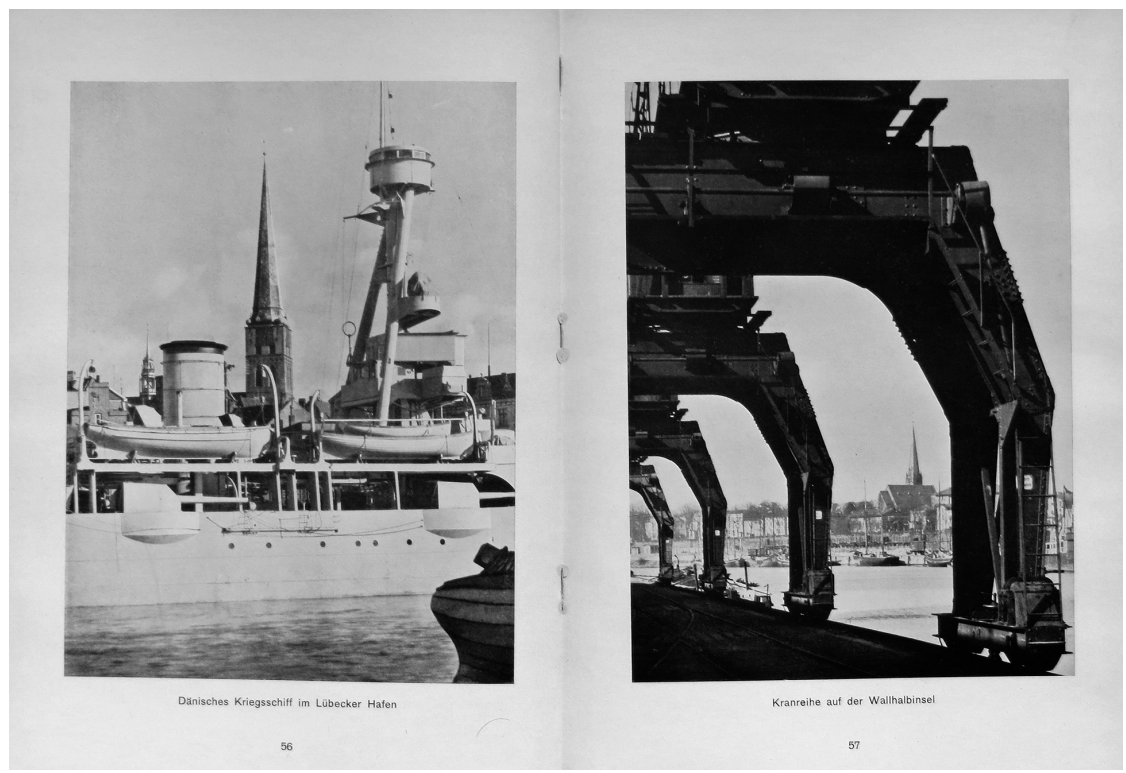

Abb. 4: Lübeck. Achtrig photographische Aufnahmen von Albert Renger-Patzsch, hg. von Ernst Timm, Berlin 1928, Tafel 56f.

Neuem und den Rhythmus der Formen auf Renger-Patzschs Bildern, um historische Bedeutung aus der Verwandtschaft von moderner und mittelalterlicher Gestalt zu ziehen. Benjamin war, als er über den Flaneur schrieb, nicht an solchen Formalismen interessiert; er suchte vielmehr nach den schockhaften Zusammenstößen von Alt und Neu. Für Kracauer gilt dasselbe. Die Vorliebe für ein Netz von Bezügen, das erst unter dem Blick des aufmerksamen Besuchers Bedeutung erhält, ist aber auch bei Heise zu greifen, der sich noch nicht einmal eingesteht, wie sehr dieses Netz nur zwischen den Buchdeckeln Bestand hat.

Die Bedeutung der Flanerie im Werk eben jener Schriftsteller der Zwischenkriegszeit, die auch so viel wie kaum ein anderer Zeitgenosse zu unserem theoretischen Verständnis der modernen Fotografie beigetragen haben, ist gut bekannt. Für die dabei vorherrschende Vorstellung vom Medium ist es wohl bezeichnend, dass sie mit Debatten über städtische Erfahrung und die Leistung von Oberflächenlektüre in den Schriften derselben Leute einherging. Im Zusammenhang mit seinen Kommentaren über die Allegorie im Trauerspielbuch, dessen Niederschrift auf 1925 zurückgeht, setzt Benjamin die Beziehung einer Idee zu den Dingen mit der Beziehung eines Sternbilds 
zu den Einzelsternen gleich. ${ }^{6}$ Ideen sind hier also nicht transzendental. Sie sind vielmehr das Ergebnis eines Zugriffs des Gedankens auf die Dinge selbst und schulden ihre Existenz dem Prozess einer Lektüre der Oberflächenwirklichkeit. Eine solche Auslegung wird Benjamins komplexen erkenntnistheoretischen Überlegungen im Trauerspiel zwar nicht gerecht. Sie hilft aber bei der Erläuterung seiner damals in Entwicklung befindlichen und auch von anderen Schriftstellern der Weimarer Zeit - sei es auch theoretisch weniger anspruchsvoll und oft mit anderen Zielen - in Anwendung gebrachten physiognomischen Strategie. Physiognomik in Benjamins Verständnis will den Erscheinungen der äußeren Wirklichkeit eine verborgene Bedeutung abgewinnen, indem sie in ihnen Bestandteile eines Kulturzusammenhangs sieht. Sie beruht auf der Annahme, dass es in Raum und Zeit andere Verbindungen zwischen den Erscheinungen gibt, als dem Alltagsverständnis zugänglich sind. Auf dieser Grundlage hat physiognomische Lektüre gleichzeitig eine Dekonstruktion von Allerweltsannahmen über die Orte von Dingen und Ereignissen in der Welt und, anstelle dieser Allerweltsannahmen, die Konstruktion anderer Verknüpfungen dieser Dinge zu liefern. Ähnlichkeit und Beziehung der Erscheinungen treten in diesem Prozess als Schlüsselkriterien an die Stelle, die in der hergebrachten Physiognomik die Beziehung des Individuums zum Typ eingenommen hatte. Immer noch steht wie in jener die Möglichkeit, vom Äußeren aufs Innere zu schließen, auf dem Prüfstand. Aber an die Stelle des Selbstausdrucks eines Subjekts, den Physiognomen traditionellerweise voraussetzen zu dürfen meinten, tritt der Anspruch auf die Bestimmung eines übergreifenden Ausdruckszusammenhangs durch den Physiognomiker. 1929 stellt sich Benjamin die Aufgabe, "äußerste Konkretheit« in der Beschreibung eines ganzen Zeitalters zu gewinnen; später spricht er von den Beziehungen der Dinge zur Geschichte und Erinnerung als Konstellationen, die »blitzhaft« ein Bild der Erkenntnis erzeugen, und will Jahreszahlen »ihre Physiognomie« geben. ${ }^{7}$ Die Interessen von Historikern

6 Vgl. Walter Benjamin: Ursprung des deutschen Trauerspiels [1928], in: ders.: Abhandlungen (Gesammelte Schriften I), hg. von Rolf Tiedemann und Hermann Schweppenhäuser, 3 Bde., Frankfurt a.M. 1974, Bd. 1, S. 203-430, hier S. 214.

7 Ders.: Brief an Gershom Scholem vom 15. März 1929, in: ders.: Gesammelte Briefe, hg. von Christoph Gödde und Henri Lonitz, 6 Bde., Frankfurt a.M. 1995-2000, Bd. 3, S. 453-456, hier S. 454, und ders.: Das Passagenwerk (Gesammelte Schriften V), hg. von Rolf Tiedemann, Frankfurt a.M. 1982, S. 576f. und 595, vgl. auch ebd., S. 573f. Siehe außerdem Susan Buck-Morss: The Dialectics of Seeing. Walter Benjamin and the Arcades Project, Cambridge (Mass.) 1989, S. 58ff., und Willi Bolle: Physiognomik der modernen Metropole. Geschichtsdarstellung bei Walter Benjamin, Köln 1994, bes. S. $30 \mathrm{ff}$. 
und Physiognomikern überlagern sich in seinen Augen. Sichtbare Erscheinungen sind jeweils das Studienobjekt, und Abbilder dieser Erscheinungen sind Speicher eines besonderen Wissensvorrats.

Richard T. Gray behauptet, dass in der Zwischenkriegszeit die Physiognomik eine sSuperdisziplin der Bedeutungserzeugung geworden sei und einen der Aufklärungserzählung von der Vernunft und dem geistigem Fortschritt der Menschheit widersprechenden Denkansatz geboten habe. ${ }^{8}$ Das ist einerseits richtig. Aber Physiognomik betrieben auch die Vertreter des politisch linken Flügels, die durchaus Vernunft- und Fortschrittglauben auf ihre Fahnen geschrieben hatten. Noch dazu darf man die Grenzen zwischen der hergebrachten Gesichtslektüre und einer kritischen Kulturphysiognomik nicht allzu deutlich ziehen. Gray zeigt sich verwundert darüber, dass Benjamin lobende Wort für die Bemühungen des 18. Jahrhunderts um die Physiognomik findet. Jede Erklärung dieser Tatsache muss in Rechnung stellen, dass Benjamin dasselbe Verfahren einer Lektüre von Gesichtern nicht nur guthieß, wie seine vielzitierte Begeisterung über August Sanders 1929 erschienenes Antlitz der Zeit erweist, sondern auch selbst erprobte. ${ }^{9}$ Vor allem widmete er sich aber wie Kracauer und andere zeitgenössische Denker einer physiognomischen Lektüre von Oberflächen der Dinge und scheinbar oberflächlichen Dingen, Ereignissen und Strömungen der Gegenwart. Er bediente sich dabei zuweilen einerseits des Stadtplans, für ihn Speicher für das genaueste Wissen »vom Ganzen«, und andererseits der Fotografie, die »das genaueste Wissen vom Einzelnen" aufbewahrt. Auf diese Weise konnte er etwa dazu kommen, eine Fotografie von Sasha Stone zum Ausgangspunkt einer kulturkritischen Glosse über altmodische bürgerliche Inneneinrichtungen zu machen und dabei noch den "Charakter«, den solche zum Schauplatz von Verbrechen

8 Vgl. Richard T. Gray: About Face. German Physiognomic Thought from Lavater to Auschwitz, Detroit 2004, S. 180f. Matthias Uecker: The Face of the Weimar Republic. Photography, Physiognomy, and Propaganda in Weimar Germany, in: Monatshefte 99 (2007), S. 469-484, untersucht physiognomische Bilderbücher, jedoch ohne dabei den Bereich Stadtwahrnehmung zu berücksichtigen.

9 Vgl. ders.: About Face, S. 219f., unter Berufung auf Walter Benjamin: Das Paris des Second Empire bei Charles Baudelaire [1938], in: ders.: Abhandlungen, Bd. 2, S. 511-604, hier S. 541. Siehe auch ders.: Kleine Geschichte der Fotografie [1931], in: ders.: Aufsätze, Essays, Vorträge (Gesammelte Schriften II), hg. von Rolf Tiedemann und Hermann Schweppenhäuser, 3 Bde., Frankfurt a.M. 1977, Bd. 1, S. 368-385, hier S. 381. Hinweise auf Benjamins eigene physiognomische Lektüre von Gesichtern gibt Wolfgang Brückle: Kein Portrait mehr? Physiognomik in der deutschen Bildnisphotographie um 1930, in: Gesichter der Weimarer Republik. Eine physiognomische Kulturgeschichte, hg. von Claudia Schmölders und Sander Gilman, Köln 2000, S. 131-155, bes. S. 135 und 137. 
ausersehene Räume hätten, zu beschwören. ${ }^{10}$ Auf dieselbe physiognomische Weise las er auch die Straße und die Stadt überhaupt. In seiner Beschreibung von Fotografien des Buchs über Moskau aus der oben erwähnten Reihe von Städteporträts erscheint unter seinem Blick die Erlöserkirche "nichtssagend wie ein Zarengesicht", und Mauerzinnen erinnern in ihrer Süßigkeit und Rohheit an ein russisches Frauenantlitz - vielleicht das auf dem Schutzumschlag und einer Tafel im Buch erscheinende Gesicht (Abb. 5). ${ }^{11}$ Hier entsteht der Eindruck, dass die Abbildung der Dinge erst den Drang zu ihrer Belehnung mit Ausdruck hervorrief. Tatsächlich unterstützt Benjamin selbst die Vermutung, dass ihm die Betrachtung von Fotografien zur Übertragung von physiognomischem Wissen auf die Stadterscheinung verhalf. Denn er bekennt von der Fotografie eines Moskauer Museums, dass nur auf ihr das Gebäude, das ihn bei seinem Besuch der Stadt noch an Charlottenburg erinnert habe, wirklich zu einem Bestandteil Moskaus geworden sei. Lesern der Buchbesprechung muss diese Behauptung rätselhaft erschienen sein. Nur wer mit Benjamins Bericht aus Moskau vertraut war, erkannte vielleicht in ihr einen Widerhall seines Eindrucks, dass der Reisende, bevor er die Fremde begreift, angesichts ihrer zuerst die eigene Heimat zu sehen lernt. ${ }^{12}$ Das kleine intertextuelle Selbstgespräch lässt sich für Benjamins Verständnis des Gebrauchswerts von fotografischen Bildern

10 Walter Benjamin: Paris, die Stadt im Spiegel [1929], in: ders.: Kleine Prosa. BaudelaireÜbertragungen (Gesammelte Schriften IV), 2 Bde., hg. von Tillman Rexroth, Frankfurt a.M. 1972, Bd. 1, S. 356-359, hier S. 357, und ders.: Einbahnstraße [1926], in: ders.: Kleine Prosa, S. 83-148, hier S. 88f. Der Vorschlag, in Stones Fotografie Benjamins Anregung zu sehen, steht schon bei Detlev Schöttker: Benjamins Bilderwelten. Objekte, Theorien, Wirkungen, in: Schrift, Bilder, Denken. Walter Benjamin und die Künste, hg. von dems., Berlin 2004, S. 10-29, S. 18. Die Einschreibung eines jeweils bestimmten Charakters in ganze Räume geht auf das späte 18. Jahrhundert zurück; damals versuchte erstmals ein Museumsleiter seine Säle so einzurichten, dass deren Gesamterscheinung die "Physiognomie" vergangener Jahrhunderte zeige. Vgl. Wolfgang Brückle: Aux racines de la mise en scène historiciste. Observations sur les premières décennies de l'art médiéval dans un contexte muséal, in: Un musée révolutionnaire. Le musée des Monuments français d'Alexandre Lenoir, hg. von Geneviève Bresc-Bautier und Béatrice de Chancel-Bardelot, Paris 2016, S. 271-281, bes. S. 273.

11 Ders.: Besprechung von Alexys A. Sidorows 'Moskau< [1928], in: ders.: Kritiken und Rezensionen (Gesammelte Schriften III), hg. von Hella Tiedemann-Bartels, Frankfurt a.M. 1972, S. 142-143. Das Gesicht auf dem Schutzumschlag zeigt allerdings eher ein Mädchen als eine Frau. Das Moskau-Buch behandelt auch Roland Jaeger: Ein Bilderkompendium aller Weltstädte. Die Reihe »Das Gesicht der Städte« im Albertus-Verlag, Berlin, in: Autopsie. Deutschsprachige Fotobücher 1918 bis 1945, hg. von dems. und Roland Jaeger, 2 Bde., Göttingen 2012-2015, Bd. 1, S. 202-217, S. $209 f$.

Vgl. ders.: Moskau [1927], in: ders.: Kleine Prosa, S. 316-348, hier S. 316. 


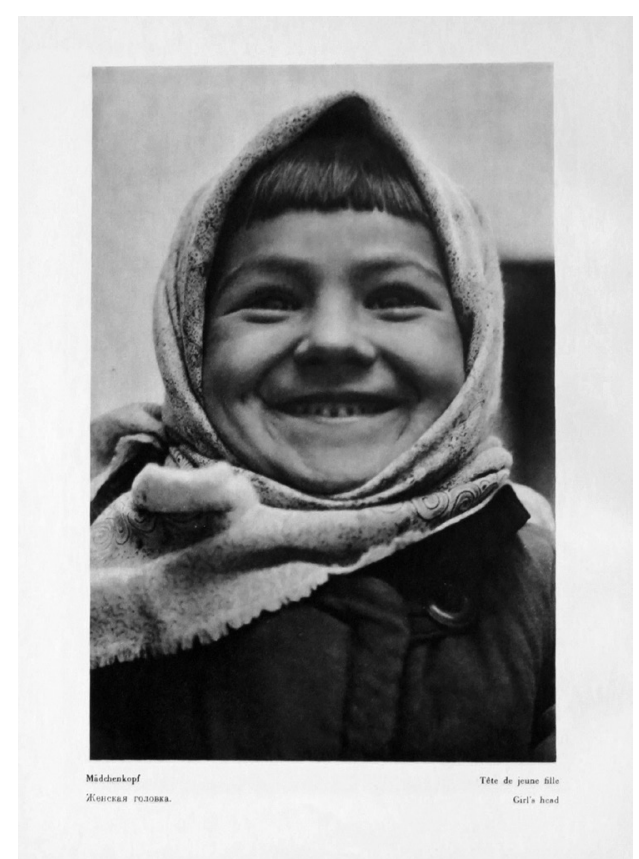

Abb. 5: Alexys A. Sidorow: Moskau, Berlin 1928, Tafel 130

fruchtbar machen. Erst im Nachhinein, glaubt Benjamin, erschließt sich dem Physiognomiker der Sinn der Wirklichkeit; Fotografien befördern die physiognomische Lektüre, indem sie deren Betrachtung im Nachhinein erlauben. Diese Ermunterung zur Physiognomik speist sich, so scheint es, aus der zwiespältigen Rolle der Fotografie als bloßes Aufzeichnungswerkzeug und als Mittel für die Repräsentation der Welt, die Ausdruckskraft schon durch die Tatsache ihrer Wiedererscheinung als Bild erhält.

In einer Würdigung von Hessels schriftstellerischem Ansatz schreibt ihm Benjamin die Neigung zu »Chronik, Dokument, Detail« zu, leicht erkennbar auch Eigenschaften, die im medientheoretischen Diskurs mit der Fotografie verbunden werden. ${ }^{13}$ Es kommt insofern nicht überraschend, dass eine Fotografin Hessel und ihn auf ihren Spaziergängen durch Berlin zu begleiteten pflegte. Man hat vermutet, dass es sich bei ihr um Germaine Krull gehandelt habe. Das ist möglich, aber nicht zwingend. Beide Männer kannten Mari-

13 Ders.: Die Wiederkehr des Flaneurs [1929], in: ders.: Kritiken und Rezensionen, S. 194199, hier S. 194. 
anne Breslauer, die am Berliner Lette-Haus eine Ausbildung als Fotografin durchlaufen hatte und berichtet, dass sie Hessel oft in der Stadt herumfuhr. Gelegentlich war aber auch Doris von Schönthan dabei, kurzzeitig Hessels Geliebte und ebenfalls werdende Fotografin, von deren eigenen Bildern sich allerdings anscheinend nichts erhalten hat; von ihrer Vorliebe für stille Gassen und alte Leute auf Parkbänken können wir nur aus Hessels Beschreibungen eine Vorstellung gewinnen. ${ }^{14}$ Zum Glück beschränken sich unsere Kenntnisse geteilter Stadterfahrungen von Schriftstellern und Fotografen nicht auf dieses Wissen um persönliche Bekanntschaft und um Schönthans von Hessel überlieferten Wunsch, ihre Fotografien zusammen mit Texten von seiner Hand zu veröffentlichen. Hessel hat nämlich, durch seinen Parisaufenthalt von 1927 angeregt, gemeinsam mit Krull tatsächlich veröffentlicht: Im selben Jahr erschien in Das Illustrierte Blatt ein Aufsatz von seiner Hand über das immer in Wandlung befindliche Antlitz der Stadt, und sie gab Fotos aus Pariser Straßen dazu (Abb. 6). Die einzelnen Bilder unterscheiden sich in der Herangehensweise voneinander, und wenigstens eins von ihnen verdankt sich wohl auch einem anderen Anlass. Denn neben Fotografien von Werbeplakaten, die etwas nachlässig wie im Vorbeigehen entstanden zu sein scheinen, taucht ein pathetischer und dabei sehr vom willkürlich gewählten Standpunkt des Subjekts geprägter Blick in das Eisengefüge des Eiffelturms auf, aus der Untersicht und damit unter abstrahierender Verunklärung aller räumlichen Verhältnisse. Aber gerade in dieser Verschiebung der Bildauffassung passt die Sequenz genau zu Hessels Darstellungsabsichten. Denn seine Auffassung von den titelgebenden "Architekturen des Augenblicks« ist doppelsinnig, indem er darin das modernistische Konzept einer Wahrnehmung

14 Vgl. Marianne Feilchenfeldt-Breslauer: Bilder meines Lebens. Erinnerungen, Wädenswil 2009, S. 170f.; Magali Laure Nieradka: Der Meister der leisen Töne. Biographie des Dichters Franz Hessel, Oldenburg 2003, S. 86 (Breslauer) und S. 120f. (Schönthan) sowie Walter Benjamin: Verstreute Notizen Juni bis Oktober 1928, in: ders.: Fragmente vermischten Inhalts. Autobiographische Schriften (Gesammelte Schriften VI), hg. von Rolf Tiedemann und Hermann Schweppenhäuser, Frankfurt a.M. 1985, S. 415-418, hier S. 415, vgl. auch S. 790. Siehe außerdem ders.: Berliner Chronik [1932], in: ders.: Fragmente vermischten Inhalts, S. 465-519, hier S. 470. Ausflüge mit Schönthan beschreibt Franz Hessel: Unsere fleißigen Mädchen [1930], in: ders.: Städte und Porträts (Sämtliche Werke Bd. 3), hg. von Bernhard Echte, Oldenburg 1999, S. 269-272, hier S. 270. Hessels Tagebuch ist aber auch zu entnehmen, dass Krull ihn in Berlin begleitete, vgl. Franz Hessel, Tagebuchnotizen (1928-1932), in: Juni 3 (1989), Nr. 1, S. 36-49, hier S. 40. Sie war auch mit Benjamin bekannt, wie ein von ihm selbst gezeichneter Stammbaum seiner Bekanntschaften bezeugt, vgl. ebd. S. 41, und Benjamin, wie oben, S. 804. Ein Bildnis Doris von Schönthans als Modell für Hutmoden veröffentlichte der Querschnitt 7 (1927), Nr. 5, Tafel nach S. 366. 


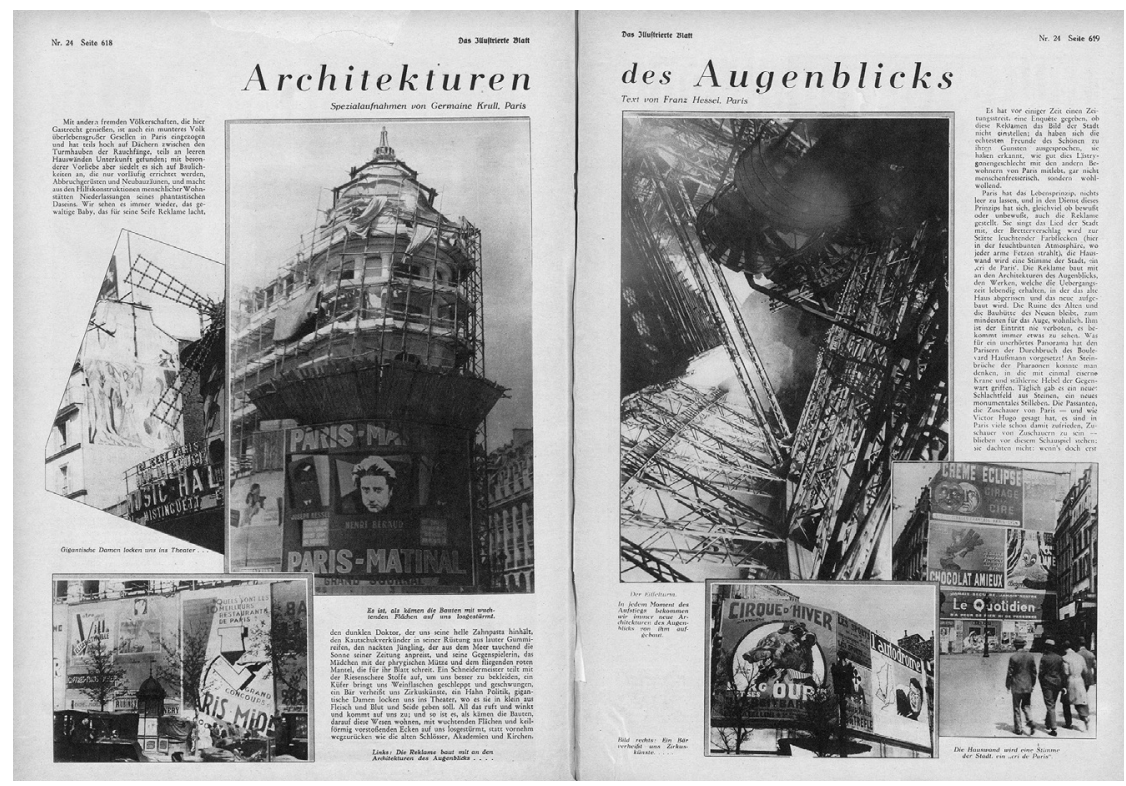

Abb. 6: Doppelseite aus Franz Hessel: Architekturen des Augenblicks, in: Das Illustrierte Blatt 15 (1927), Nr. 24, S. 618f.

in ständiger Bewegung und seine eher idiosynkratische Aufmerksamkeit für die proteische Physiognomie der Fassaden mit deren riesigen und kurzlebigen Werbeplakaten verbindet. ${ }^{15}$ Der Beitrag hätte durchaus ohne Bilder erscheinen können. Aber der Untertitel zeigt unter Hintanstellung von Hessels Miturheberschaft an, dass Krull "Spezialaufnahmen« beitrug. Was heißt das? Man stößt oft auf ähnliche Umschreibungen in den Zeitschriften der Zeit, und ihre Bedeutung ist nicht immer ganz gleich. Manchmal wird der Leser auf ungewöhnliche Bildtechniken verwiesen oder auf den besonders

15 Vgl. Franz Hessel: Architekturen des Augenblicks [1927], in: ders.: Städte und Porträts, S. 340-341. Zu Krulls ersten Unternehmungen in Paris hatte eine avantgardistisch aufgefasste Reihe von Fotografien des Eiffelturms aus unterschiedlichen Blickwinkeln gehört. Über deren Entstehungsdatum besteht Uneinigkeit, vgl. mit weiteren Angaben Wolfgang Brückle: Germaine Krull. Métal, in: Journal für Kunstgeschichte 8 (2004), S. 385-388, bes. S. 387, sowie jüngst Michel Frizot: Germaine Krull, Berlin 2015, S. 42. Ein Typoskript im Benjamin-Archiv der Berliner Akademie der Künste führt unter anderen Beiträgen Architekturen des Zufalls (Plakate) auf; es handelt sich dabei offensichtlich um denselben Text. Vgl. Ernest Wichner/Herbert Wiesner: Franz Hessel. Nur was uns anschaut, sehen wir, Berlin 1998, S. 97. 


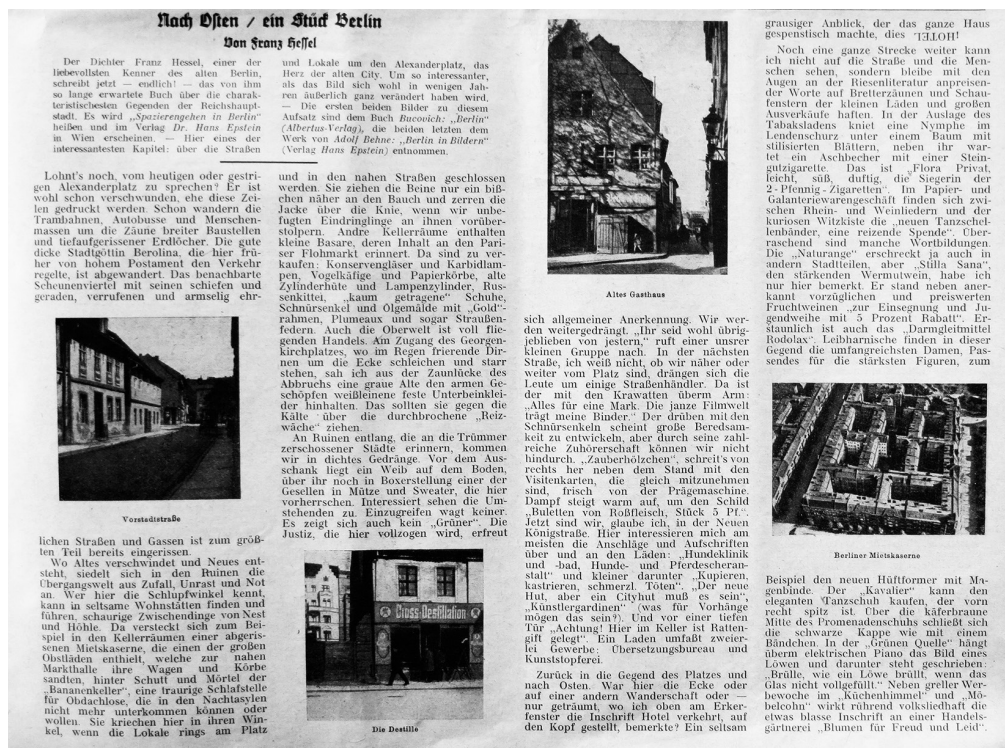

Abb. 7: Franz Hessel: Nach Osten, in: Die literarische Welt 5 (1929), Nr. 13/14, S. 3

tollkühnen Einsatz des Fotografen. In diesem Fall gilt das - vielleicht mit der Ausnahme des Bilds vom Eiffelturm - aber nicht. Man muss deshalb vermuten, dass eher die enge Zusammenarbeit der beiden Urheber betont werden soll, vielleicht sogar auf einem gemeinsamen Ausflug, dessen Ergebnis Text und Bilder sind.

Allerdings ging Hessel bei anderer Gelegenheit anders vor. 1929 brachte Das Illustrierte Blatt einen doppelseitigen Bericht, in dem Umbehrs surreal angehauchte Bilder von Mannequins außer Gebrauch mit einem Text von Hessel verbunden werden. ${ }^{16}$ Ob Hessel die Bilder überhaupt gesehen hat, als er seinen Text schrieb, bleibt unklar. Das gilt erst recht, als Die literarische Welt den Vorabdruck eines Kapitels aus seinem Buch Spazieren in Berlin bringt und um vier Bilder aus zwei jüngst erschienenen Büchern über Berlin, eines davon Bestandteil der oben erwähnten Reihe "Gesicht der Städte«, ergänzt (Abb. 7). Die Bilder sind über die Seite verstreut und zeigen mit einer Ausnahme Straßen fast ohne Leben, als wollten sie Bühnen für die imaginären Spaziergänge der Leser bieten. Hessel erwähnt keinen der abgebildeten Orte.

16 Vgl. ders.: Eine gefährliche Straße, in: Das Illustrierte Blatt 17 (1929), S. 686-688. 


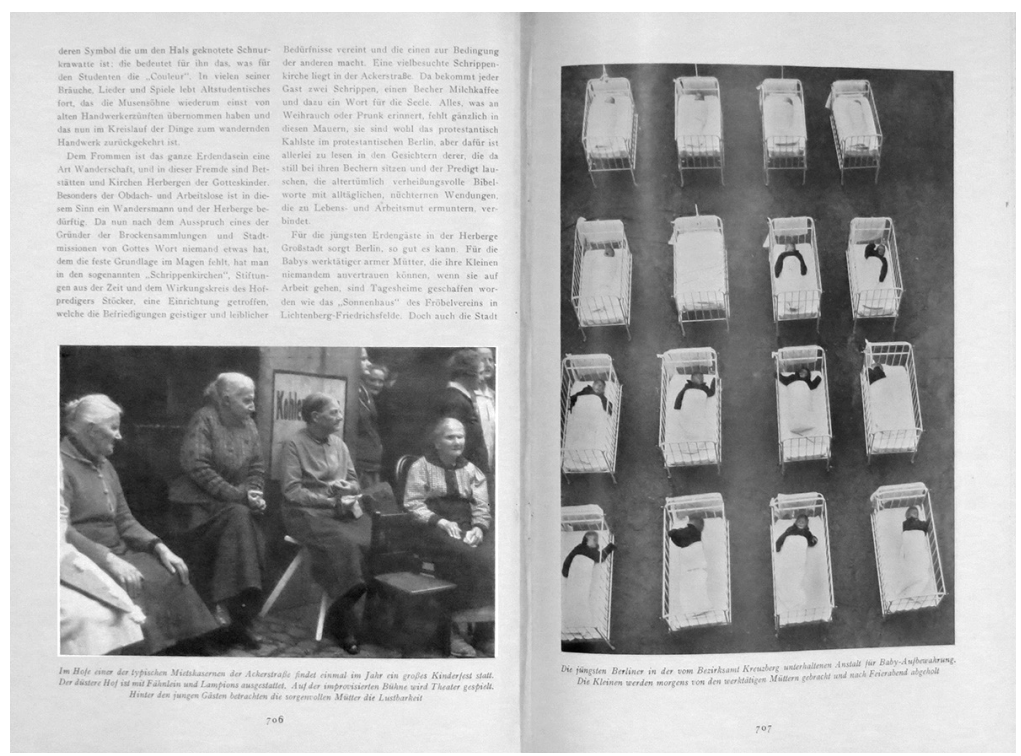

Abb. 8: Franz Hessel: Herberge und Heimat. Bilder aus Berlin, in: Atlantis 2 (1930), S. $706 f$.

Es ist also in diesem Fall anzunehmen, dass er beim Schreiben die Bilder gar nicht vor sich gehabt hat. Bei wieder anderer Gelegenheit saß Hessel aber mit Fotografien vor Augen am Schreibtisch. Davon zeugt sein Beitrag über Berlin als »Herberge und Heimat«, geschrieben für die Zürcher Zeitschrift Atlantis auf der Grundlage von Abzügen, die vermutlich eine Bildagentur geliefert hatte (Abb. 8). Hessel beschreibt nach eigenem Urteil »dokumentarisch«, was auf den Fotografien zu sehen ist, wenn auch ohne Übereinstimmung mit der Reihenfolge in der gedruckten Bildstrecke. ${ }^{17}$ Anscheinend weist er sogar auf seine Vorgehensweise hin, indem er in der Schwebe lässt, ob sich der Untertitel Bilder aus Berlin auf seine Sätze oder auf deren Vorlage bezieht. In Wahrheit ist beides richtig. Hessel schrieb wie Benjamin Stadtbilder. Er schrieb über Bilder, oft implizite, und erzeugte seinerseits Bilder. Der Schutzumschlag seiner Nachfeier von 1929 erhielt eine Inhaltsangabe, die

17 Ders.: Herberge und Heimat. Bilder aus Berlin, in: Atlantis 2 (1930), S. 705-717. Eine der Fotografien stammt von Umbehr, dessen Urheberschaft jedoch nicht ausgewiesen wird. Vgl. Herbert Molderings: Umbo, Tafel 66. Für die Bezeichnung der eigenen Schreibweise als »dokumentarisch" siehe Franz Hessel: Frauen und Städte [entworfen nach 1935], in: ders.: Städte und Porträts, S. 193-203, hier S. 198. 


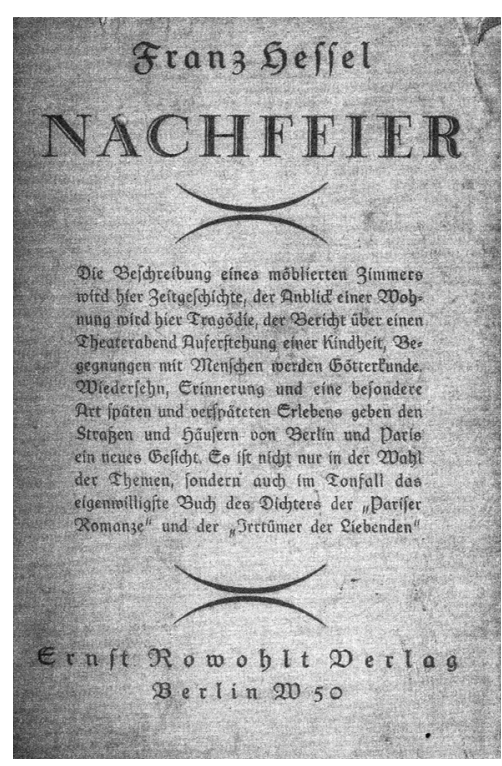

Abb. 9: Schutzumschlag von Franz

Hessel: Nachfeier, Berlin 1929 schon in der offensichtlichen Ähnlichkeit mit Benjamins oben erwähnter Beschwörung eines bürgerlichen Wohnraums das Physiognomische des Verfahrens offen zutage treten lässt (Abb. 9). Die Beschreibung eines möblierten Zimmers wird, so heißt es da, "Zeitgeschichte« und der Anblick einer Wohnung »Tragödie«; verspätetes Erleben gebe Straßen und Häusern von Berlin und Paris »ein neues Gesicht«. Hessels im selben Jahr erschienenes Buch Spazieren in Berlin stellt gemäß dem Umschlagtext sogar »ein Bilderbuch in Worten" dar. Die Arbeit mit Abbildungen kommt also nicht von ungefähr. Eine nachträgliche, aber eigenhändige Randnotiz vermerkt, dass sein um oder nach 1930 entwor-

fener Text über einen Pariser Flohmarkt "wohl zu Photos als Begleittext" geschrieben wurde. Möglicherweise hatte diese Fotografien Krull geliefert. ${ }^{18}$ In Hessels Nachlass findet sich außerdem eine Liste von Unterschriften für Bilder von ihr. Sie beschreiben das Treiben in der Rue Mouffetard, wie es auch Gegenstand eines anderen ausführlicheren Texts von Hessel ist. Eine davon lautet, charakteristisch für Hessels Bedeutungsfindung: »Die Ruinen alter Mauern bleiben stehn und bekommen im Zwielicht die Schön-

18 Vgl. ders.: Frauen und Städte, S. 201, sowie ebd. S. 202 für einen ähnlichen Hinweis auf die Verbindung seiner Beschreibung des Eiffelturms mit Fotografien. Hessel verfasste diese Erläuterungen nach dem Scheitern einer Neuveröffentlichung in Buchform. Für keinen der Aufsätze konnte bisher eine Veröffentlichung zu Hessels Lebzeiten nachgewiesen werden, und es ist unklar, ob Krull jeweils für die Fotografien zuständig war. Es liegt aber in beiden Fällen nahe, denn einem ihrer Bilder vom Eiffelturm begegnen wir in Architekturen des Augenblicks, und den Pariser Flohmarkt hat sie ebenfalls fotografiert. Vgl. Florent Fels: Les mystères de la Foire aux Puces, in: Vu 1 (1928), S. 306-307, mit sieben Bildern von Krull. Krull hat außerdem Fotografien für den von Hessels Frau mitverfassten Aufsatz Araber in Paris beigesteuert. Siehe auch Michael Opitz: Frauen und Städte. Ein unrealisiertes Buchprojekt von Franz Hessel, in: "Genieße froh, was du nicht hast«. Der Flaneur Franz Hessel, hg. von Michael Opitz und Jörg Plath, Würzburg 1997, S. 157-189, bes. S. 184f. 
heit von Tempelresten. ${ }^{19}$ Hier spricht sich der in Hessels Werk der späten 1920er Jahre zu beobachtende Übergang vom Mythos zur Beschwörung geschichtlicher Tiefe aus. Zwei weitere Bildunterschriften vereinigen sich zu einem Satz, woraus hervorgeht, dass Hessel den Text zu bereits vorliegenden Bildern schrieb, also einen regelrechten Bildessay, in dem ihm die Sorge für eine narrative Zusammenziehung vorliegender Einzeleindrücke zukam. Eine Veröffentlichung ist wohl nicht zustande gekommen, und eine ursprünglich zusammengehörige Sequenz von Krulls Bildern aus der Rue Mouffetard ist nicht bekannt. Eine in Krulls Paris-Bilderbuch von 1929 veröffentlichte Aufnahme der Straße zeugt von einer Bildauffassung, wie wir sie in Ermangelung besserer Begriffe üblicherweise als >dokumentarisch bezeichnen (Abb. 10). Krull war für ihre avantgardistische Fotografie berühmt geworden. Aber am Ende der 1920er Jahre wandte sie sich einem formal weniger ehrgeizigen Stil zu, offensichtlich unter dem Eindruck der damals für Eugène Atget herrschenden Begeisterung und im Einklang mit einer Tendenzwende im Werk einiger Kollegen. Es gibt viele Gründe für die-

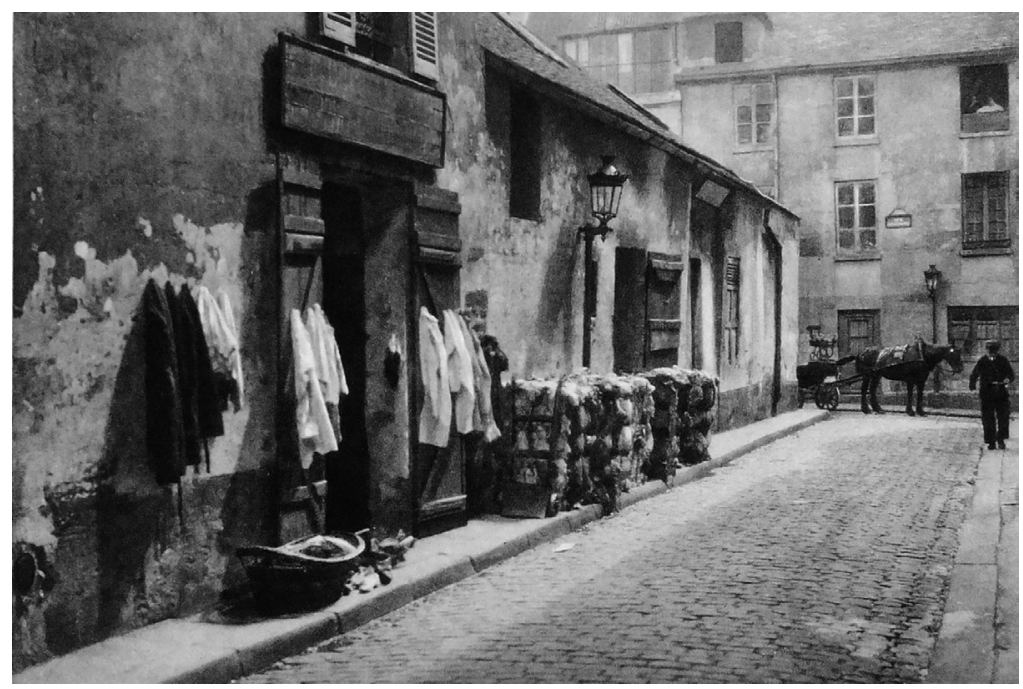

Abb. 10: Germaine Krull: Rue Mouffetard, Fotografie, um 1928, hier nach dies.: 100 x Paris, Berlin 1929, S. 90

19 Die 23 Bildunterschriften finden sich vollständig in: Franz Hessel: Städte und Porträts, S. 402f. (mit der zitierten Unterschrift als Nr. 3). 
sen Paradigmenwechsel..$^{20}$ Für unseren Zusammenhang ist nur bedeutsam, dass gerade die scheinbare Gleichgültigkeit einer als Dokument aufgefassten Fotografie den physiognomischen Blick begünstigte, denn sie förderte auf dem Bild selbst die Wiedergabe von Zufälligem und damit Komplexität, während sie auf Seiten des Betrachters die Bereitschaft, dieser Komplexität soziologische, historische, allegorische oder surreale Bedeutung zu geben, unterstützen konnte. Benjamin hat sich, wenn auch nur nebenbei, ganz in diesem Sinn über Krulls Fotografien geäußert. ${ }^{21} \mathrm{Im}$ selben Zusammenhang will er die Einengung der Fotografie überwinden, indem er die Klischees der sie begleitenden Reportagetexte durch bloße Beschriftung der Bilder zu ersetzen vorschlägt. Genau daran hat sich Hessel versucht, als er seine Folge von Bildlegenden für Krull zusammenstellte.

Bei der beschriebenen Art des Umgangs mit Fotografie haben wir es natürlich immer mit Ausnahmen von der Regel zu tun. Als Renger-Patzsch und Martin Munkácsi im Uhu darauf aufmerksam machen, dass auch Laienfotografen durch richtigen Gebrauch des Apparats ein »Kulturdokument« hervorbringen können, ist das für sie wohl nicht mehr als ein kleines Gedankenspiel (Abb. 11). ${ }^{22}$ Jedenfalls sucht man nach einer solchen Aufgabenstellung in beider Werk, das oben erwähnte Bilderbuch über Lübeck eingeschlossen, fast vergebens. Andererseits kann unter dem kritischen physiognomischen Blick, den sich einige Zeitgenossen angewöhnt hatten, fast jedes Bild ein lesbares Gesicht bekommen. Bekanntlich betonte Kracauer immer wieder die Entfremdung des Individuums von der Welt, mitverursacht durch Fotografien als Hauptbestandteil der großen Bilderflut. Sie lenken von der Wirklichkeit ab, sagt er; sie führen in die Irre; sie enthalten nicht die wahre Bedeutung des Moments, den sie bewahren sollen. Kracauer spricht hier allerdings, wie oft übersehen wird, weniger über das Medium selbst als über dessen Gebrauch

20 Siehe bes. Olivier Lugon: Le style documentaire d'August Sander à Walker Evans 19201945, Paris 2001, S. 39ff. und passim.

21 Vgl. Walter Benjamin: Fotografie, S. 383. Siehe auch Michael Schwarz: Raumgewordene Vergangenheit. Passagen und Interieur, in: Walter Benjamins Archive. Texte und Zeichen, bearb. von Ursula Marx u.a., Frankfurt a.M. 2006, S. 206-209. Im Jahr 1933 riet Dora Benjamin ihrem vormaligen Ehemann, Krull als Lieferantin von Fotografien für einen schon früher geplanten Text über Gusseisenarchitektur des 19. Jahrhunderts heranzuziehen; ein Abdruck im Uhu sei versprochen worden. Vgl. Dora Sophie Benjamin: An Walter Benjamin [7. Dezember 1933], in: Was noch begraben lag. Zu Walter Benjamins Exil. Briefe und Dokumente, hg. von Geret Luhr, Berlin 2000, S. 37f. Dora erwähnt, dass auch Stone passende Bilder gemacht habe; es hat sich aber nichts Entsprechendes erhalten.

Martin Munkacsy [sic]/Albert Renger-Patzsch: »Halt mal still«, in: Uhu 5 (1928), Nr. 10, S. 19-26, hier S. 23. 


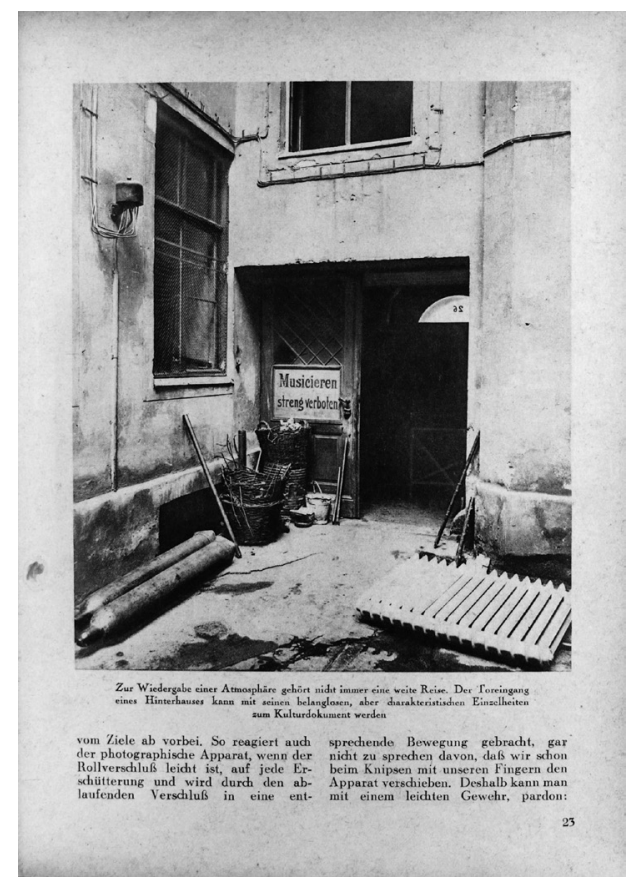

Abb. 11: Martin Munkácsi/Albert Renger-Patzsch: »Halt mal still«, in: Uhu 5 (1928), Nr. 10, S. 23

in der Massenkommunikation. Dem Film schrieb er die Fähigkeit zu, "Straßenphysiognomien« zur Aussage zu zwingen. ${ }^{23}$ Mit solchen Worten äußerte er sich über die Fotografie nie. Aber er betrachtete sie gelegentlich ebenso begeistert wie Benjamin und Hessel. Im Jahr 1930 schrieb er ein kleines Prosastück über die Wirkungen und kulturellen Implikationen der künstlichen Beleuchtung, die sich auf der Fassade der Berliner Gedächtniskirche spiegelte. Der Text trägt den Titel Ansichtspostkarte und entstand anscheinend mit einer Fotografie unter den Augen des Verfassers, ohne sich im Übrigen von anderen, nach eigenem Erlebnis der tatsächlichen Orte und Ereignisse geschriebenen Glossen zu unterscheiden. Kracauer spricht sogar, nicht ohne einen Widerspruch mit dem von ihm gewählten Titel zu riskieren, von der allmählichen Annäherung des Spaziergängers an die Kirche. Aber eigentlich

23 Siegfried Kracauer: Sturm über Asien. Zu dem Film von Pudowkin, in: ders.: Kleine Schriften zum Film (Werke 6), hg. von Inka Mülder-Bach, 3 Bde., Frankfurt a.M. 2004, Bd. 2, S. 191-195, hier S. 194. 
geht es doch nur um die Erscheinung des Gebäudes, wie eine Fotografie sie wiedergeben konnte, und um die gesellschaftliche Wirklichkeit, die sich Kracauer zufolge als "unbeabsichtigter Widerschein" zur Anschauung bringt. ${ }^{24}$ Was immer auch Kracauer 1927 über die Oberflächlichkeit der Fotografie gesagt hatte: In dieser Postkarte fand er Bedeutung, und damit in der Ausdrucksfähigkeit der Oberfläche selbst.

Ein anderer Fall von Kracauers reflexiver Medienpraxis bestätigt sein Interesse an der Fruchtbarkeit von ganz alltäglicher Fotografie. 1932 besuchte er eine Ausstellung von über tausend Bildern des eingangs erwähnten Fotografen Vennemann. Gezeigt wurden bei dieser Gelegenheit ausschließlich Aufnahmen aus Berlin. Vennemann hatte sie jahrelang nach verschiedenen Motiven und Eindrücken abgesucht. Er zeigte Straßen und Plätze, alte und neue Häuser, Hafenansichten und Fabriken, Büros und Wohngebiete, Verkehr und Arbeit, Freizeit, Parks, Sport, die Stadt bei Tag und bei Nacht in kleinem Format und in Riesenabzügen (Abb. 12). ${ }^{25}$ Kracauer ist angetan von dem, was er da zu sehen bekommt. Er erwähnt, dass die Bilder ein bisschen unbewegt aussehen, aber er übergeht die Möglichkeit, daraus auf die Biederkeit der Bildauffassung zu schließen. Stattdessen stellt er die kulturtheoretische Überlegung an, dass diese Wirkung von der Gewöhnung der Zeitgenossen an filmische Bewegung herrühren könnte, sei es an ihre eigene oder die der Kamera. Die Fotografie sieht er in diesem Prozess historisch werden. Sie verliert ihre Berührung mit der Gegenwart in einer Weise, die Kracauer einen Schatten der vergehenden Zeit selbst auf den Lichtbildern,

Ders.: Ansichtspostkarte. Kaiser-Wilhelm-Gedächtniskirche bei Nacht [1930], in: ders.: Essays, Feuilletons, Rezensionen, Bd. 3, S. 241-242, hier S. 242; siehe auch Willi Bolle: Physiognomik, S. 344f. Frederic J. Schwartz: Blind Spots. Critical Theory and the History of Art in Twentieth-Century Germany, New Haven/London 2005, S. 138ff., sieht bei Kracauer eine Absage an das physiognomische Ausdruckskonzept; oben wird dagegen auch noch der Ausdruck von Leere als Ergebnis physiognomischer Lektüre angesehen. Das macht das Gebäude bei Kracauer freilich noch nicht zu einem "Speicher für Gefühle«, wie Elizabeth Otto: Siegfried Kracauer's Two Art Histories, in: Culture in the Anteroom. The Legacies of Siegfried Kracauer, hg. von Gerd Gemünden und Johannes von Moltke, Ann Arbor 2012, S. 128-148, hier S. 142, in Ableitung von Kracauers Gedanken aus dem Expressionismus annimmt.

25 Die Ausstellung fand im vormaligen Kunstgewerbemuseum statt und wurde vermutlich von der Staatlichen Kunstbibliothek veranstaltet. Eine Beschreibung gibt Curt Glaser: 1000mal Berlin, in: Berliner Börsen-Courier vom 15. Dezember 1932, S. 6-7. Siehe auch Christine Kühn: Neues Sehen in Berlin. Fotografie der Zwanziger Jahre, Berlin 2005, S. 254, sowie Eckhardt Köhn: 1000 x Berlin. "Schöpfer des Gesichts einer Weltstadt«. Der Fotograf Albert Vennemann, Lautertal 2015, bes. S. 63 und die auf S. 58 gegebene Auswahl von Vennemanns Berliner Bildern. 


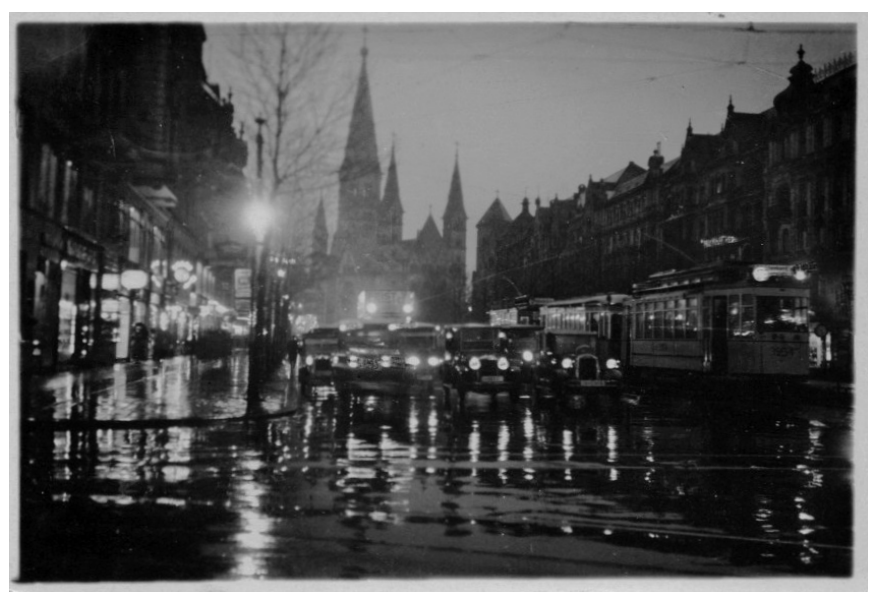

Abb. 12: Albert Vennemann: Gedächtniskirche bei Nacht, Fotografie, um 1930, zeitgenössische Postkarte

auch auf kürzlich entstandenen, spüren lässt. Die Fotografie wird für Kracauer erst, indem sie veraltet, ganz zum Besitz der Menschheit. Fotografierte Häuser und Straßen, Arbeiter und Kinder, Bahnhöfe und Denkmäler sprechen ihm zufolge vor allem das Gedächtnis an, und er will »das versunkene Bekannte« als Hauptgegenstand der Ausstellung gesehen wissen. Indem die Fotografie mit solchen Erscheinungen eine Wiederbegegnung ermöglicht, helfe sie uns, Nutzen aus Dingen, "mit denen wir unbewusst lebten", zu ziehen. ${ }^{26}$ Man hört hierin, wie schon in seinem Aufsatz über die Fotografie von 1927, Kracauers Lehre vom Zerfall widerhallen. Er will den bloßen Schein in den "Oberflächenbezirken des Alltags« als Verweis auf eine unentfremdete Wirklichkeit, die sich nur in dessen Brüchigkeit und nur als Möglichkeit ausspricht, kenntlich machen. In einer bemerkenswerten Verschiebung vom Verhältnis der Gegenwart zum Vergangenen auf das Verhältnis des Gegenstands zum Abbild kann die Fotografie erzeugen, was der Vorstellungskraft des Flaneurs anheimgestellt gewesen war, als Kracauer zwei Jahre zuvor ein Zusammentreffen der "Abfälle und Sternbilder« in seinem Erlebnis einer Pariser Straße geschildert hatte. ${ }^{27}$ Womöglich hatte er diese Formulierung

26 Siegfried Kracauer: Photographiertes Berlin [1932], in: ders.: Essays, Feuilletons, Rezensionen, Bd. 4, S. 310-312, hier S. 310 und 311.

27 Ders.: Gestalt und Zerfall [1925], in: ders.: Essays, Feuilletons, Rezensionen, Bd. 2, S. $283-$ 288, bes. S. 286, sowie ders.: Erinnerung an eine Pariser Straße [1930], in: ders.: Essays, Feuilletons, Rezensionen, Bd. 2, S. 358-364, hier S. 364. 
im Gedanken an Benjamins physiognomische Sternbild-Metapher gewählt. Dem Ansatz nach zeigte sich jedenfalls damals und zeigt sich in seiner Betrachtung von Vennemanns Fotografien noch einmal dasselbe physiognomische Verfahren eines erinnernden Sehens wie bei Benjamin und wie in Hessels Wanderungen durch Berlin und Paris. In der komplexen Beschreibung durch Fotografie und Flaneur wird auch bei Kracauer die Alltagswelt als Ansammlung von Spuren der Geschichte lesbar.

Ich habe in diesem Beitrag Beispiele für eine besondere Art des Umgangs mit Fotografie in der Erschließung von Großstadterfahrung in der Zwischenkriegszeit zusammengetragen. Man hat vielen damaligen Fotografen 'Flanerier nachgesagt, auch Vennemann und Hessels Freundin Breslauer. ${ }^{28}$ Aber die Bilder dieser Fotografen unterscheiden sich zum Teil beträchtlich, und es gilt nicht für sie alle gleichermaßen, dass sie, statt nur Ausbeute von Spaziergängen zu sein, auch zum imaginären Spaziergang im Raum der Repräsentation ermuntern. Für den Physiognomiker werden sie umso ausdrucksvoller, je weniger besorgt um 'künstlerischen Ausdruck ihre Urheber sind, und wir haben gesehen, wie sich Benjamin, Hessel und Kracauer die Erfahrung von Fotografien, die zugleich Aufzeichnung und Ausdruck zu liefern scheinen, zunutze machten. Allerdings hat sich nur Kracauer 1932 darum bemüht, diese Tatsache auch zum Gegenstand von Medienreflexion zu machen. Ich schließe mit zwei Beobachtungen. Erstens: Kracauer hat eine freudianische Sicht auf die Erfahrung von Fotografien. Schon 1927 hatte er gewisse Fotografien als Beitrag zur "Auseinandersetzung des Bewusstseins mit der Natur « bezeichnet und mit Traumarbeit in Verbindung gebracht. ${ }^{29} 1930$ und 1932 bewirken die Fotografien noch einmal eine wünschenswerte Rückkehr der ins Unterbewusstsein gesunkenen Dinge, jedoch als Erinnerung ans Gesehene beschrieben. Das entspricht der Verlagerung vom Mythos auf die Erinnerung als bedeutungsstiftenden Hintergrund von Stadterfahrung in Hessels Werk der späten 1920er Jahre und Benjamins Beschreibung der Stadt als "mnemotechnischer Behelf des einsam Spazierenden ${ }^{30}{ }^{30}$ Zweitens ist es überraschend, dass Kracauer diese Auffassung aus Anlass der Ausstellung einer fast unüberschaubaren Menge großteils eher konventioneller Bilder

28 Vgl. Florian Ebner: L'air de Paris. Die zweite fotografische Ausbildung der Marianne Breslauer, in: Marianne Breslauer. Fotografien, hg. von Kathrin Beer und Christina Feilchenfeldt, Winterthur 2010, S. 52-63, bes. S. 54; Eckhardt Köhn: Vennemann, S. 61; Wolfgang Brückle: Bummeln, S. $165 f$.

29 Siegfried Kracauer: Fotografie, S. 698

30 Walter Benjamin: Wiederkehr des Flaneurs, S. 194, und Jörg Plath: Liebhaber der Großstadt. Ästhetische Konzeptionen im Werk Franz Hessels, Paderborn 1994, S. 104. 
vertritt. In seinem Aufsatz von 1927 hatte er noch die Fragmentierung der Wirklichkeit in der modernistischen Fotografie hochleben lassen; damals schien das Neue Sehen, wenn auch von ihm nicht unter diesem Begriff angesprochen, im Widerstand gegen die Alltagswahrnehmung eine Auseinandersetzung mit der Wirklichkeit gewährleisten zu können. Vennemann kann mit dieser Tendenz nicht gut in Verbindung gebracht werden. Zwar schuf er ein paar Fotomontagen und nebenbei einige der damals beliebt werdenden Riesenabzüge. Aber mit dem Löwenanteil seiner Bilder lieferte er Postkartenmotive. Warum störte sich Kracauer daran nicht? Offenbar hatte er inzwischen seine stilistischen Vorlieben geändert. Realismus war nun wieder gefragt, auch bei ihm. Gerade die gelegentlichen Experimente des sonst eher biederen Vennemann zeigen, wie sehr die modernistische Rhetorik der Fotografie zu einer Menge bloßer Floskeln geworden war. Wohl auch deshalb wandten sich zur selben Zeit so viele Avantgardefotografen dem Dokumentarismus zu. Krulls Werk gibt dafür ein gutes Beispiel ab. Kracauer gibt mit seinen Gedankengängen ein anderes Beispiel. Bei seiner 1930 beschriebenen Ansichtspostkarte kann es sich gut um ein Bild von Vennemann gehandelt haben. Damit beginnt seine Aneignung der äußeren Wirklichkeit im Hinblick auf ganz alltägliche Fotografien. Sie erlauben ihm eine Lektüre des metaphorischen Gesichts der Wirklichkeit und eine Erfahrung von deren historischer Tiefe. Wir sehen bei ihm nicht anders als bei Benjamin und Hessel den Spaziergang mithilfe von Repräsentationen und hinein in Repräsentationen, die in den Augen der hier untersuchten Kulturphysiognomiker immer beides zugleich sind: die Erscheinung der Wirklichkeit selbst und Bilder, in denen sie sich ausdrückt. 
